\title{
Organization, Atmosphere, and Digital Technologies Designing Sensory Order
}

\author{
Jørgensen, Lydia; Holt, Robin
}

Document Version

Accepted author manuscript

Published in:

Organization

DOI:

$10.1177 / 1350508419855698$

Publication date:

2019

License

Unspecified

Citation for published version (APA):

Jørgensen, L., \& Holt, R. (2019). Organization, Atmosphere, and Digital Technologies: Designing Sensory

Order. Organization, 26(5), 673-695. https://doi.org/10.1177/1350508419855698

Link to publication in CBS Research Portal

\section{General rights}

Copyright and moral rights for the publications made accessible in the public portal are retained by the authors and/or other copyright owners and it is a condition of accessing publications that users recognise and abide by the legal requirements associated with these rights.

Take down policy

If you believe that this document breaches copyright please contact us (research.lib@cbs.dk) providing details, and we will remove access to the work immediately and investigate your claim. 


\section{Organization, Atmosphere, and Digital Technologies: Designing Sensory Order}

\section{Lydia Jergensen and Robin Holt}

Journal article (Accepted manuscript*)

\section{Please cite this article as:}

Jørgensen, L., \& Holt, R. (2019). Organization, Atmosphere, and Digital Technologies: Designing Sensory Order. Organization, 26(5), 673-695. https://doi.org/10.1177/1350508419855698

\section{DOl: https://doi.org/10.1177/1350508419855698}

Copyright (C) The Author(s) २०19. Reprinted by permission of SAGE Publications.

* This version of the article has been accepted for publication and undergone full peer review but has not been through the copyediting, typesetting, pagination and proofreading process, which may lead to differences between this version and the publisher's final version AKA Version of Record. 


\title{
Organization, Atmosphere and Digital Technologies \\ - Designing sensory order.
}

\author{
Lydia Jørgensen and Robin Holt \\ https://doi-org.esc- \\ web.lib.cbs.dk:8443/10.1177/1350508419855698
}

\begin{abstract}
We argue technology and organization are inherently spatial phenomenon. We conceptualize this conjunction as atmosphere: a gathering of mood, human practice, material and environmental conditions, and values that has sufficient coherence and distinction to constitute a distinct interior. Atmospheres, however, are not entirely stable and present: the interior is porous to outside influence, and the interior is never wholly ordered. We show this through the study of digitally mediated architectural design practice. We find the technological mediation of atmospheres is constituted in sensory and affective spatial arrangements, and not in rationally calculated configurations of assets and goals. An atmosphere is inherently aesthetic. This allows us to gesture toward a definition of organization as technologically mediated spatial struggle to reconcile interior coherence with outward exposure.
\end{abstract}


Introduction

Organization is an elusive object of study: though sometimes very palpably present it is not 'in' or 'on' anything: as an entity it eludes ostensive definition, yet as a process its determining force can constrain to the point of snuffing out life itself. It is perhaps most easily apprehended in its spatial expression in fields of sensory experience and affective, material presence (not that organization happens in space, but that it is spatial (Beyes and Steyaert, 2011)). Yet its spatiality has only recently and sporadically been the object of organizational study (Clegg and Kornberger, 2006; de Vaujany and Vaast, 2014; Shortt, 2014; Tyler and Cohen, 2010; Julmi, 2015; Borch, 2010). These studies, in part inspired by the magisterially baggy dialectical work of Henri Lefebvre, are revealing intimacies between space and organization, as O'Doherty (2008: 546) points out:

... research is beginning to realize that space is not simply a passive container or an outcome of willed, planned rational design, but an active agent in its own right and one that embodies causative powers with the potential to influence human thought and behaviour.

This spatial turn in organization studies investigates how space organizes power, how it institutionalizes, how it acts (Strati, 2010; Burell and Dale, 2008; Beyes and Steyaert, 2011). Its 'causative power', however, is as much a condition of affect as effect: space works through sensory experience and feelings. Walter 
Benjamin envisages this affective spatial presence as inherently technological. The sensorium is riddled with and transformed by mediating devices such as radio, books, or glass and steel buildings organising perceptive fields, bodily gestures, and emotional feelings.

Taking this to heart, this study investigates the mediation of sensory stimulation and emotional expectation as an organizational condition, one conceptualized as atmosphere (Böhme, 1995; Sloterdijk, 2004). It follows an architectural practice using digital technologies to afford a sensory engineering of interior space in the transition of offices between locations in Denmark. Politically, aesthetically and administratively speaking, it is an everyday affair, nothing spectacular. We show how the design of atmospheres emerge from the use of performative digitally produced visualisation of the kinesthetic and synesthetic qualities ${ }^{1}$ of an imagined organizational space. We further show how these mediated experiences configure and cohere in ways that can evoke an entire organizational space, bringing in collective and historical memory, ideas of authority, and individual aspiration and anxieties; in doing so we reveal causative spatial powers as atmospheric.

\section{Space and organization}

Reckwitz (2016) observes social theory regards its primary subject matter as action (or more latterly communication) and norms (or more latterly signs and meaning producing sign systems), an elevation that confines spatial, sensory and affective experience to an immediate and everyday condition that

\footnotetext{
1 Synesthetic and kinesthetic qualities are key elements of atmosphere and should be understood in reference to notion of atmosphere (Böhme, 1995; Schmitz, 2014)
} 
matters only insofar as they contribute to the ordering what is being done and communicated, and to what might be done and communicated were things organized differently. Set against the study of power, class systems and alienation, gender, or markets, concern for the everyday world of spatial and sensual experience evoke what is backward, incidental and antique. Compared to the characters and plot, the settings, sensory experiences and feelings associated with these dramas are bit role players, at best.

Yet consider what organization is - the process of tool use through which organisms relate states of cohesiveness (inwardness) to states of potential (outwardness) - and we realize any proper apprehension of organizational change is predicated on studying the mediating forms of perception and affect by which people apprehend this inward/outward movement (Martin, 2003).

Take the media thinking of Walter Benjamin $(1999: 23,32)$ as an almost peerless example. In studying the social order of mid-nineteenth century bourgeois capitalism Benjamin (1999: 852; 864) asks how consumers might feel in the shopping arcades - architectural and mercantile glass and iron veins in which interiors were animated with sanitized exteriors. It is a study of capitalism concentrating on the human sensorium: how were actions, norms, communications (and signs) experienced through bodies, feelings, stylistic expressions and collective sensitivities. How did one body relate to another? How did buildings open and restrict access, how did light, too, come and go? They worked by inducing a sense of mannered style and convenience which both demanded and excited bourgeois conformity to which shoppers aspired. Yet they lasted barely a generation. They were outgrown by new tastes for 'the open air' enabled by wider pavements and the advent of electric street lighting; no matter 
how clean the windows the interiors no longer shone, but became sad and dirty (Benjamin, 1999: 121; 858)

Benjamin's analysis is an explicative attempt to reveal and study the spatial nature of being in the world: how organization is a continual spatial consolidation and projection of interior forms whose cohesiveness (inward integrity) and potential (outward permeability) are mediated technologically. These forms are riven with both social and sensual orders of their time (Reckwitz, 2016: 63; Sloterdijk, 2017: 143f.).

In a similar spirit Reinhold Martin (2003) argued patterns of selforganising individualism were being steadily mirrored in the contagious spread of curtain walled office buildings (an architectural extension of the glass arcades). The open plan office systems accompanying the high rise office blocks enabled by curtain wall construction methods carried the promise of flexibility and individuality yet as interiors they were little more than folded-in exteriors. One machine and operator were connected to the next, one office, one building, one district, and so on, each unit becoming absorbed into "concatenations of social, biological, technological and aesthetic space" (Martin, 1998: 106). Through studying the architecture, we are made aware of changes not only of organizational form, but also in forms of understanding organization that tally with the emergence of cybernetics, systems thinking and communication theory. And as media change and become digital, Martin finds the visible regularity of such repetition unravelling into processes: moulds of managerialism gave way to patterns of modulating free enterprise in which networks of human-machine assemblages form and reform as patterns of data flow in open sites of control (Martin, 2003; 38-41) 
What we also learn from Martin (2003: 12) is an awareness that these forms of spatial analysis refuse as much as encourages generalities. What would it be to generalize space anyhow? Is it not already everywhere? For Henri Lefebvre (1974/1991: 7-8) being suspicious of the generalising concept, and staying with everyday experience, was critical for spatial understanding, resisting the temptation to convert the minor histories, indigenous skills and haphazard events of technologically mediated spatial production into broad conceptual messages (this or that type of organizational force) and to treat organized inhabitation of space as reading of those messages.

\section{Space and atmosphere}

So what conceptual framing can we use? To study organization spatially is not just to work with the documents, treatises and ideas of how insides are designed (as Martin does admirably), but also to take up more directly forms of phenomenological study that remain with words, images and things themselves, as they are found and used in multiple interiors, whilst accepting these words, images and things cannot be readily removed from either the structures and symbols in which they appear, or from the affects (intimacy, exposure, protection, etc.) they produce (Ash \& Simpson, 2016; Julmi, 2015). As Sloterdijk (2012: 18f.) argues, researchers might seek refinement by examining the immediate and mediated spatial experience of being thrown into life; they are to apprehend atmospheres (Sloterdijk, 2004; Böhme, 1995; Zumthor, 2005; Schmitz, 2014).

Architecture - the realization of order through the spatial expression of organizational forms - is the practice in which atmosphere receives its most attention. As an interior form, atmosphere carries, and casts itself through, 
multiple forces: the historical, the normative, the aesthetic, the social, or the cultural. For Peter Zumthor (2005: 11) atmosphere is the grounding concern of architectural practice. Zumthor talks, for example, of buildings emerging from an energy of conjunctions between: hard and soft edges, natural and artificial light, insides going outside and outsides coming in, and scale that cautions yet pulls one in. Framed atmospherically, in understanding a building there is little to be gained from analysis of technical specifications, technological components, or stated functional goals. It is, rather, found in developing sensitivity to the mediations and moods of an existing space, from which acts of atmospheric translation become possible.

Atmospheres can be described as 'envelopments' and 'ways of beingtogether' (Anderson, 2016:148), in which (non)sentient things and their situation are thrown together and mutually encoded through continually, if often subtly, morphing patterns of felt expression engagement, sometimes almost invisibly in habit, at other times in discord (Sloterdijk, 2004: 945). For phenomenologists Gernot Böhme (1995: 172ff; 2001: 73ff;) and Hermann Schmitz (2014: 66) these patterns are akin to moods, and becoming aware of mood is an experience of atunement. Space becomes an existential experience, it concerns a sensory-affective attunement to moods. For both Schmitz and Böhme, invoking their Heideggerian heritage, mood forms an existential background constitutive of common, felt meanings circulating within an atmosphere (Böhme, 2013: 121ff.; Schmitz, 2014: 21f.),

\section{Imagining atmosphere}

Böhme (2013: 110) and Schmitz (2014: 18) suggest atmosphere only 
lives when its movement is affectively alive to what Lefebvre (1974/1991) calls the excesses and redundancies of lived space (inwardness exposed to outwardness). This is not to exclude the conscious use of technology, or even to be cautious in its use, but to be conscious of affording it a scope extending human reach. All architectural design employs technology in some way or another, notably Computer Aided Design. In the designing atmospheres, however, such technologies provide embodied experience spatial sensoriums of the future.

As Ihde (2009a: 467) recognizes there is huge imaginative potential in these digital visualizations: they explore where design can go rather than enforcing already agreed ideas: 'only insofar as our instruments transform experience are they of use or interest'. Ihde's work connects pragmatism, phenomenology and technoscience (Tripathi, 2015), and gives heft to Zumptor's and Böhme’s (1995: 2013) aesthetic concern with atmosphere by emphasizing the intimacy between body, social practice, space, atmosphere and embodied experience. Ihde is acutely attentive to the mediating role technology plays in the production of the sensory and affective qualities of atmosphere, not least in the way technologies become incorporated as extensions of the human body (Tripathi, 2015: 202).

For Idhe (2009b: 33f.) this felt, technological, bodily grounding of experience has a number of ontological qualities. First, the usefulness of things is relational and not intrinsic: things are not tools-in-themselves, their use-value emerges from pragmatic needs, for instance attuning a buildings' light levels to the organisms inhabiting it. Secondly, to use things skilfully and knowingly is not to reveal but conceal them, as when cotton blinds are drawn unthinkingly over a window, or, increasingly, mechanically; technology is most pervasive when it is 
least present. Rather than cognitively isolate and define things the fullest awareness of the thing comes when it loses its edges and functions seamlessly with other systems, becoming mediations of experience rather than distinct objects (Ihde, 2009b: 43). And thirdly, in this concealment wider systems of social and natural mediation are revealed: closing cotton blinds reveals, for example, lifestyles organized by norms of privacy.

For Hansen (2006) these ontological qualities entail shifts of phenomenological concern: away from isolated acts of perception and toward sensory atunement. Like Ihde, Hansen is alive to how technology, especially digital, is actualized affectively through embodied inhabitation, it is more than what appears through perception. So in architectural practice, by blending physicalities with systems of algorithmic computation, architecture can reconceive its function as a practice of atmospheric design through, in part, the mediation of 'wearable spaces' (Hansen, 2006: 178). Here the sensing and affective human body remains a grounding presence, and the technology employed to create possible atmospheres is set amid other things through whose mediation emerge modifications and modulations of this body, extending itself outside itself, attuning to moods of other spaces, imaginary and actual, and bringing them inwards into sensory and affective reach. It is this spatial restlessness of the body that technology affords and augments, and through which an analogue as much as a digital creation of atmospheres can emerge. The inwards/outwards movement is critical. If affective, spatial patterns that enjoin to the contrasts and accidents of lived experience are closed off by an atmosphere, one unable to find its own interior form in in relation to its outward setting (Böhme, 2013: 110; Schmitz, 2014: 29), then it becomes a contrivance of 
explicit order. Something Lefebvre (1992/2004: 15) argues has become increasingly prevalent in organizational settings where feelings of exhaustion have often become more palpable than those of growth and innovation.

\section{Designing atmosphere}

Böhme acknowledges the risks of creating such denuded atmospheres, such as those envisaged, for example, under the cloche of totalitarian regimes (Bille et al., 2013; Böhme, 2013: 162ff; Heibach, 2012), or more prosaically, the design of branding atmospheres aimed at manipulating consumption patterns (Julmi, 2016; Biel-Missahl, 2012). For Böhme, (1995: 97; 2013: 105; 2014: 8), as for Zumthor, architectural design ought tune atmospheres allowing both inward and outward movements that shape processes, relations and siutations ((Anderson and Ash, 2015: 78; Von Borries (2017: 15f.).

Architecture provides a stage, a condition for atmospheres to emanate (Böhme, 1995: 2013). It is the arrangement of light, colour, sound, material surfaces etc. that create a scenographic totality under which atmospheres appear and enable a mood-inducing embodied experience of the space. Especially the kinaesthetic and synaesthetic qualities combined in a totality is what allows atmospheres to emanate and create an sensory embodied experience of a certain mood.

The rise of digital technologies and computational design in architecture has manifested itself in rapid developments of software programs and packages. Aksamijas (2016: 81) categorizes this computer-aided architectural design (CAAD) software, which we condense: 


\begin{tabular}{|l|l|l|l|l|}
\hline $\begin{array}{l}\text { CAD and 3D } \\
\text { modelling }\end{array}$ & BIM $^{2}$ & Visualizations & $\begin{array}{l}\text { Parametric } \\
\text { design/form } \\
\text { generation }\end{array}$ & $\begin{array}{l}\text { Simulation } \\
\text { tools }\end{array}$ \\
\hline AutoCAD & ArchiCAD & Atlantis & CATIA & DAYSIM \\
\hline $\begin{array}{l}\text { Google } \\
\text { Sketchup }\end{array}$ & Microstation & Flamingo & Dynamo & $\begin{array}{l}\text { ENERGIE } \\
\text { Planner }\end{array}$ \\
\hline $\begin{array}{l}\text { Rhinoceros } \\
\text { 3D }\end{array}$ & Revit & RenderWorks & Grasshopper & EnergyPlus \\
\hline Spirit & Vectorworks & V-ray & SolidWorks & Radiance \\
\hline
\end{tabular}

Table 1. Categories of CAAD. After Aksamija (2016: 81)

Aksamija's five categories of CAAD reflect the range of technically mediated design options, where our interest is how the contribute in the design of atmosphere. Applications, like Microstation, allow digital representations of physical and functional characteristics of a building space. The software is at times interoperable e.g. visualization engines are used by 3D modelling applications (Aksamija, 2016: 82). The use value of these tools, however, relies on factors like the competences and skills of the users (Kolarevic, 2001: 463), the price of licenses, the enthusiasm of clients, the integration of technologies like Google, Excel, and the reliance placed on them as distinct from other traditional media such as drawing.

So whilst it has been argued that the move away from hand-made drawings and physical models means working with and design space differently, the switch from analogue to digital is not necessarily a totalising change (Kolarevic, 2001: 123; Oxman, 2017: 7), and this is not just a case of using traditional methods alongside the digital, but also what the digital is used for. As Henderson points out many design practices are characterised by mixing analogue and digital practises (Henderson, 1998). 2-D CAD, 3-D modelling and

2 BIM stands for Building Information Modelling. 
rendering etc. provide sophisticated ways to communicate spatial ideas, but so does skilled drawing and images.

Visual communication in most design processes allows different forms of communication and knowledge, including tacit knowledge, but also displays a strong visual literacy by (architectural) designers (Henderson, 1998: 204; Pottharst,1998: 64). The differences that do show is the move from the quantified production of building proportions toward a more performative visualization in which the immersive qualities of space, or atmosphere take precedence (Clear, 2013: 74f; Pallasmaa, 2014; Zumthor, 2005). Such visual (re)presentations facilitate group thinking, eliciting a.o. tacit knowledge, as they allow for negotiating space if they are performative or what Henderson's mentions as meta-indexical qualities (1998: 199). Hence visualization is less a reductive, mimetic process, and more an affective experience allowing for interaction and feedback where sensory experience becomes the means to apprehend data sets, opening users up to non-linear discovery (Diamond, 2010: 15; Schmidt, 2016: 31). The atmosphere is created through relational interaction which is of both a social and sensory order, a sensory and affective spatial process that disassembles the mimetic representation of space. These changes in digital technology, according to Carpo, challenges both core Modernist architectural principles (2016: 83) and architectural authorship (2013: 58).

Our study examines how architects in their design process make use of digital technologies to create a performative staging of information and ideas creating sensory experiences providing for exploration and discovery that feedback into the design process, realising a dynamic organizational spatial design. To date, studies have investigated the sensory and affective quality of 
spatial design in interior design and marketing (Sloane, 2014; Biehl-Missal et al., 2012) and building (Degen et al., 2017; Charitos et al., 2016).

\section{Methodology}

Just as the immersive design of atmospheres cannot itself be mediated by mimetic representations, nor can its study. Considering the design process not as a logical linear process, but rather a relation of multiple procedures, is also embodied in Yaneva's (2009: 26) and Potthast's (1998) architectural ethnographies. In Yaneva's ANT-driven study many different objects and processes are followed, and granted agental equivalence to the directing weight of the architects: the tools use them as much as they use tools (Yaneva, 2017: 34).

Inspired by Yaneva's architectural ethnography, we studied everyday interactions of technology, humans, materialities, feelings and perceptions, all of which gathered to realize design. We tracked sequences in design processes, isolating conscious (explicit) and collective situations of technologically configured interaction, situations that are typically overlooked (Yaneva 2009: 118). Where Yaneva's architectural ethnography emphasized processes and how technologies were used/involved in generating interior design, however, our approach is extended to sensory and affective aspects in the design. In this we drew inspiration from both Michels \& Steyaert's (2016) and Pink et al.s (2014) empirical work on the making of atmospheres. Specifically, we were attentive to how senses were mobilized by technology by influencing both what and how something is perceived (Reckwitz, 2016: 62f.; Sumartojo et al., 2016), and to how moods and feelings were revealed and considered from within everyday 
situations in which office users and architects met and attended to how a future space might appear in use. This allowed us to apprehend embodied sensations of affective involvement (Hasse, 2014: 232) where we concentrated on moments of tool use accompanied by expressions of attentiveness, excitement, and frustration.

The empirical material was collected by the first author in a Danish architecture firm during 2017 as it worked on an office move of different clients. The firm has 12 employees, mainly architects. The majority of projects are in Denmark across various sectors and concerning both private and public organizations. Inspired by architects like Zumthor and Pallasmaa, they concentrate on creating everyday spaces whose mood and atmosphere embodies the story and nature of an organization through its continual production of space. Specifically, our empirics concentrate on the design of interior space in this regard. Though interior design is traditionally considered a supplementary embellishment of architecture (Sloane, 2014: 300) here it is integral.

The empirics emerge from participant observations, primarily two interior design projects with two organizations, one in March-May 2017, the other May-December 2017, visited one day per week, following stages of the design process, gaining insight into specific workflows of professional architectural practice. In the first project the client, an engineering company, talked to values associated with skill, smartness and movement, and in the second the client, a cultural institution, talked to values of affection and diversity. The participant observation was mainly done in the architectural studio, however in the second project two user-workshops with the commissioning client were attended. 
In the workshops with clients, participation was mainly observation, whereas studio participation had a more apprentice-like role, being involved conceptual discussions and helping with minor tasks. Materials gathered included visuals, project documents, recordings of project-discussions and semistructured interviews with the two project managing architects as well as the studios partnering architect. Further informal talks followed-up on emerging themes and clarified questions emerging from the design process that were not self-evident to the researcher. The informal information, and sensory and affective experiences were documented in field notes. Especially the field notes, transcript of project meetings and photos have been used in the analysis on the mediating quality of technologies, since they grasped situations and immediate reactions in the design process.

Through extended and iterative conversations both authors examined the empirical material looking for intersections between technology and affectivesensory responses, going to theory on atmosphere, space and organization, and then back to the empirics. Then situations where technology played a conscious and collective role in the design process, were selected and these further analysed for sensory-affective expression, which gave us the empirical condition from which to conceptually abstract. In line with Yaneva (2009: 26), the architects' work and design process were described by the researchers, which thereby does not reflect the studios own understanding of their design process. By way of participant observation in researching atmosphere, attention was further paid to the researchers' own affective-embodied experience, as a way to learn about the experiential worlds (Michels, 2015: 259). This impacts in relation to the empirical situations identified and how these have been 
interpreted. Table 2 presents the empirical material gathered.

\begin{tabular}{|l|l|l|l|}
\hline Type & Number & Participants & Documentation \\
\hline Studio visit & $\begin{array}{l}20 \text { full } \\
\text { days }\end{array}$ & $\begin{array}{l}\text { Project-manager \& } \\
\text { project-member }\end{array}$ & $\begin{array}{l}\text { Field notes(FN) } \\
\text { Visuals( Photos\&Video) } \\
\text { Working } \\
\text { documents( DesignGuide, } \\
\text { Printouts, } \\
\text { Microstation/Rhino etc.) } \\
\text { Audio recording } \\
\text { (ProjectMeetings) }\end{array}$ \\
\hline $\begin{array}{l}\text { Workshop } \\
\text { (project 2) }\end{array}$ & $\begin{array}{l}2 \text { (1 day + } \\
1 / 2 \text { day) }\end{array}$ & $\begin{array}{l}\text { Client organization (7- } \\
10 \text { pers.), project } \\
\text { manager, CEO }\end{array}$ & $\begin{array}{l}\text { Field notes(FN) } \\
\text { Visuals(Photos) } \\
\text { Presentations(PowerPoint; } \\
\text { PostIts) }\end{array}$ \\
\hline Interview & $\begin{array}{l}3(\mathrm{x} 1,5 \\
\text { hours) }\end{array}$ & $\begin{array}{l}\text { Project-manager }+ \\
\text { partnering architect }\end{array}$ & $\begin{array}{l}\text { Audio recording } \\
\text { Notes }\end{array}$ \\
\hline
\end{tabular}

Table 2: Empirical material

Findings: design processes and digital technologies

Both projects involved creating internal space for an organization transferring to a new facility. The design process considered layout, furnishing, colouring, lighting etc, to produce space coinciding with aims of functionality and creating an evocative environment resonating with the client organization values. Central in the design process was ongoing involvement of clients and relevant professionals. The client was responsible for construction.

We concentrate on three situations where digital technology was used to mediate sensory-affective experiences as part of the design process. They describe situations in the design process that occurred equally across projects in the architectural studio. Each reflects different elements in the design process, but are not exhaustive of all the design work. The first situation shows the 
development of design parameters, connecting them to the sensory level of moods by means of visualizations, based on material from the second project The second situation shows how the use of 3D modelling in organizing sensory spatial experiences, reflecting a situation in the first project. The third situation shows how design scenarios of spatial layouts are used to convey an embodied experience of the spatial organization, referring to the second project.

\section{Designing moods}

In both projects a design guide presented a set of moods presented in words and visuals as part of the defined design parameters. Parameters, following Wiertelarz (2015: 46), frame the design and its performance, specifying a trade-off between costs, risks, functions and form. Functional requirements and the given building structure were also part of driving and defining the design. However, the architects were explicit that a guiding concern for their interior design was mood. ${ }^{3}$ The analysis illustrates how designing by moods is a non-linear process, where visualizations and digital technologies makes it possible to explore where the design could go.

The design of moods was a constant reference-point in the design process, but also something that developed as part of formulating the design parameters. The architects held a number of meetings and workshops with the client for the second project. Here the architects explained the importance of mood, separating it from what organizations might want to signal to the world.

3 The distinction between mood and atmosphere is here used interchangeably, although the concepts theoretically can be distinguished. In the two projects followed, one used mood (Design guide in Danish) and the other atmosphere (Design guide in English). This seems partly reflect a language issue reflecting different connotations across language and culture. 
The first workshop was based on a combination of presentations by the architects and group work. Based on group work, the participants jointly discussed how they used and shared their current work spaces, what worked, what didn't. The architect facilitating the work shop underlined that sharing space is not easy, while exemplifying how easy it is to fix space, addressing the automatic fixed seating of the participants. Flexibility, the architect explained, however enables a variation of moods, so people can find themselves, their own place in the common environment. The facilitating architect added that architectural design ultimately is 'about how you interact with the building. How I am in the world.' (FN-06-17). The architects approach to space showed as an existential dimension, which was further manifested at the second work shop where the facilitating architect emphasised that 'mood is where you get into the gut'. Explaining further that this allowed them 'to get down to the practical level' of the design (FN-08-17).

Where the example from the workshop showed the argument for working with moods as a design parameter, unfolding of the moods was done throughout the design process. A central first step was the architects preparatory conversations and work shop with the commissioning clients to conceptually articulate organizational values and moods reflecting the potential atmospheric experience of the finalised design, which in the second project a.o. evolved around terms of affection.

In the architectural studio the architects worked to analyse and interpret moods, as 'non-measurable' drivers, into visualisations. Sitting with their laptop or using their I-phones, the architects surfed Google and Pinterest together with their own digital archives, containing pictures of e.g. work spaces, chairs etc, to 
come up with visual interpretations. On one occasion the project group went through the archives based on memories, searching Google and Pinterest through words, associations and specific sites to find an image that could evoke the conceptualized mood in question. The image below shows a typical work situation in the office.

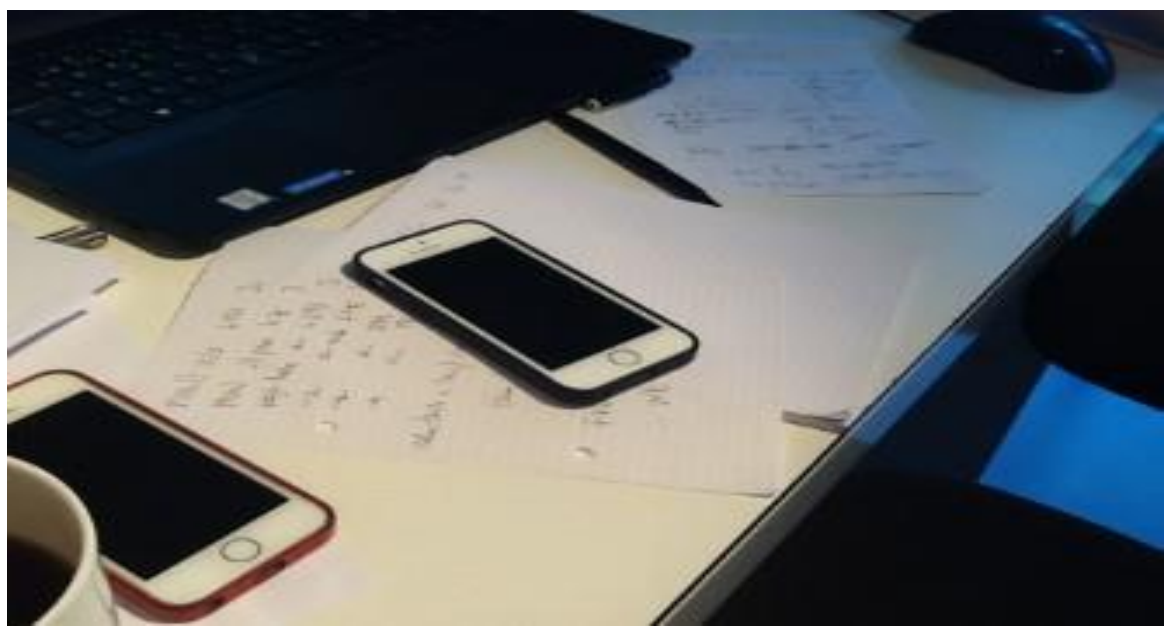

Image 1: Technologies at hand (photo by researcher)

While searching, the two architects, continuously discussed the pictures and the affective sensations attached. This fostered associative searches, where i.e. Pinterest archives gave access to other people's visual data on their affective visualizations. In their search they were guided by the words provided by the organizations, where the values of affection in relation to the organization's work was explicated in phrases like 'we're truly passionate'. As part of the analysis further wording was added, like 'humanly', 'the finish', 'tactile' and 'caring'. These words were used to find images as interpretations of the sensoryaffective qualities, the mood, that the organisation aimed for in the final design. Transforming the abstractions of passion and care into a visualization of the mood was the close-up image of wooden furniture (DG-05-17). 


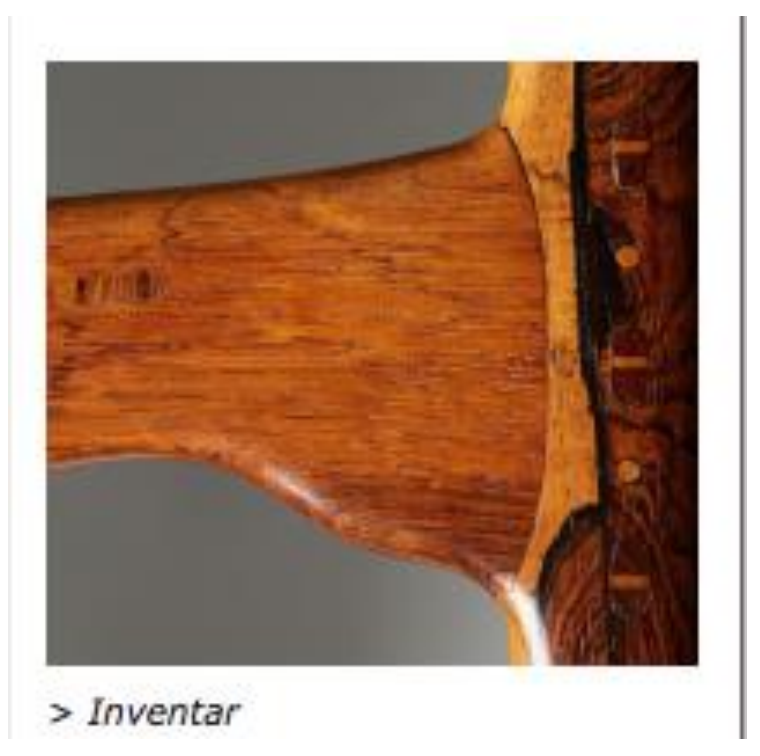

Image 2: Mood-visualisation (DG-05-17)

The words were used to find images as interpretations of the sensoryaffective qualities rather than exact representations, to create a sense of the affective space that the organisation aimed for in the final design. In this way the design parameter concerning words of affection, visualized with a chair, one evoking the client's everyday passions, but also harking back to a long-standing, tradition in Denmark of furnishing homes with well-made lasting furniture (Hansen, 2018). The close-up of a wooden chair joint, at least in Danish context, will for many evoke traces of homeliness and collective caring. As the lead architect on the second project said: 'Their words, those we have transformed into..()..something soft and nice. But it is a question of interpretation.' (I-01-18). Designing moods the architects didn't aim at generating spaces being evaluated by beautiful/ugly, but spaces that felt right for the organization. Something that the organization can relate to, bodily. Using Pinterest presented itself as a vast archive of affective associations that visualize moods and atmospheres stemming from the everydayness of other people and what they 
find interesting. A medium like Pinterest allowed users to trace multiple visual interpretations opening several, and at times surprising, trajectories for the design, but also creates a social proof by the number of pins to an image. The architects explained how, in image-centred society, Pinterest images, often of very good quality, were important to gain an affective-visual experience and to help the organizations imagine the sensory-affective qualities of the future space. That architects were observed taking some care over the size and quality of the images they gathered, alive to how the qualities of the photos played an important role in conveying mood and feeling (FN-07-17).. The image, but also its performative qualities, presented a visualization of a sensorium. Working with the visualisation of moods allowed clients to 'feel' how they want to be in the world, how they would want to interact with the building. Using digital technologies in this first phases of the design process aided the recall of embodied sensations, both for the architect and clients. Technologies like Pinterest provide a medium for opening the trajectories of the design through socially acknowledged visualizations, reflecting an archival structure based on the messiness of the everyday, where things are tagged as you go along.

\section{Immersive space}

Another persisting aspect of both projects was working with 3D modelling to study the kinaesthetic qualities of the desired atmosphere. The architects used Rhino, a 3D modelling software creating mathematical representations of a space's/objects' three-dimensional surface (with two employees formally trained to create models). The architects regarded 3D modelling as indispensable, because clients expect it and because it helped the 
clients to understand. This indispensability created challenges, as one architect said 'although it looks easy to do 3D, it takes a lot of time' (FN-03-17). The work with 3D modelling was done in the architects studio.

One of the architects, specialised in Rhino, had started preparing the 3D model, which at the early stages presented major structures such as walls, staircases, and the doors of existing spaces. Together with the other architect, the project manager, they joined in a common discussion of model (FN-04-17). The two architects gathered around the computer screen going in and out of the model, twisting perspectives, all the while gesturing at the screen, discussing the possible flow of people, light and noise. They played with the future space by altering perspectives and adding elements, drawing-on experiences from the physical visits and the photo documentation of the existing spaces.

Engaging with the space the project manager was thoughtful: 'How do you move in this area?' pointing at a part of model. The question was followed by a pause and a speculative gaze - seemingly the architect recalled how it might feel to move in that area - then a determined voice 'you would walk here', pointing at the apparent restrictions offered by walls, seating arrangements, making the finger embody the movement foreseen. The two architects continued to lean towards the joint screen, while pointing at the 3D model, discussing the kinaesthetic qualities of the space. The project manager continued exploring the space and its invitations: 'The lines are how you walk. Should you be able to pass by here or in another place (ed. indicating a passage between desk rows)? A question followed by another pause, where the two architects looked at each other, at the screen, slightly moving their bodies. Another affective comment followed as the project manager stated 'I don't feel like having people just 
wallowing in here?' (FN-04-17). Other passages between rows of working stations were also sensed as too invasive. The 3D specialist started reworking the space in the model. The work stations, the passages were rearranged to get another flow that was less invasive, that felt right. In discussing what should feel right, the architects referred to creating a sense of i.e. respect and collaboration referring to moods to be interpreted.

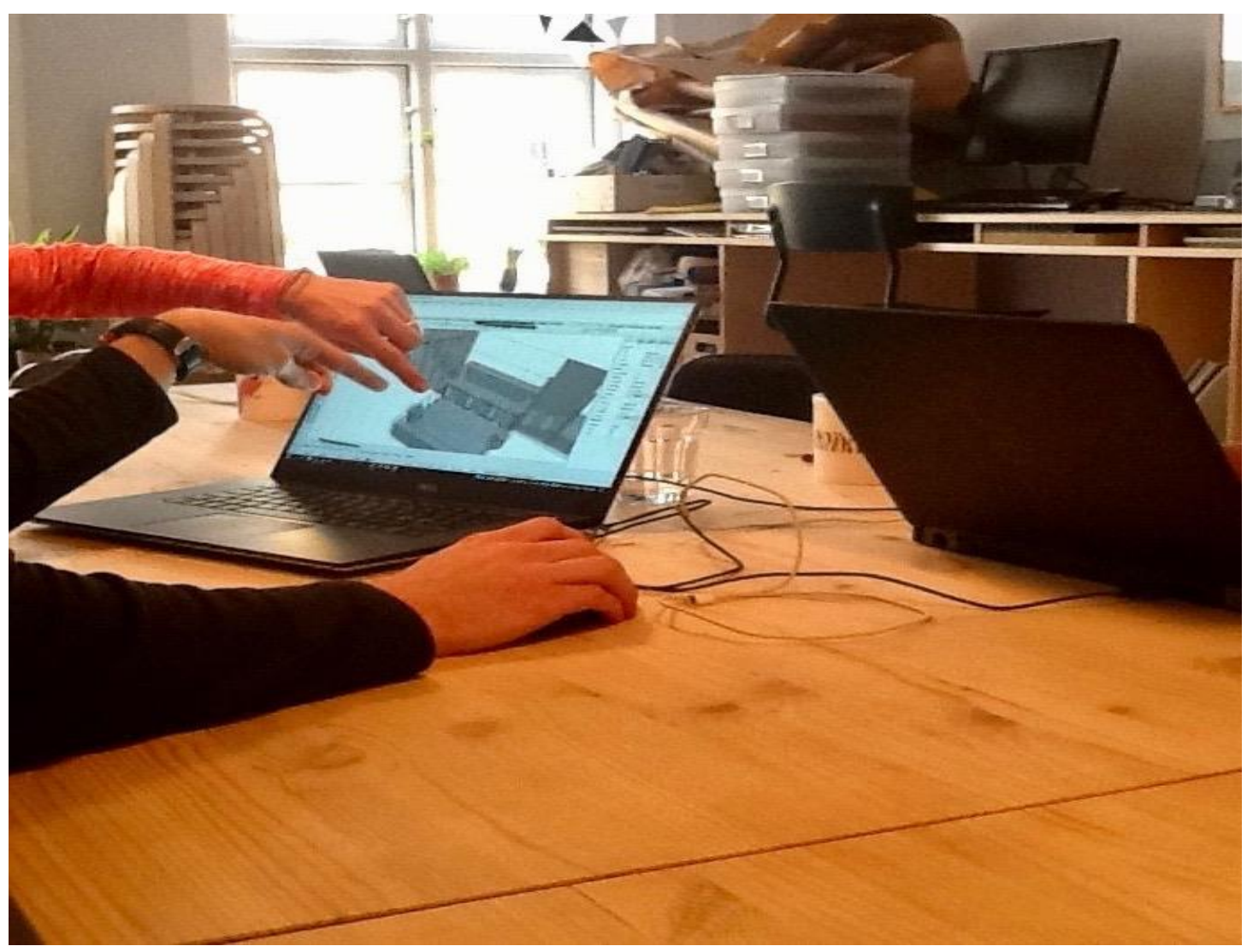

Image 3: Immersive working with 3D (photo by researcher)

Working with the 3D model presented the given conditions of the space allowing the architects to navigate the space from different perspectives to get a sense of the directions the design might take, like how fixed pillars can dissect space and shape invitations for movement. Such features were then considered 
in relation to the design parameters, whether they might support or challenge the design and mood to be evoked. For the architects the model mediated embodied kinaesthetic sensations of sensory-affective quality by envisaging how a space can both close in and open out. In this way the model afforded immersive visual experience, placing the architects into the possible flows of interior space made possible by their inputs.

Further on in the design process the model was elaborated by adding furniture details, where 3D rendering skewed the design to more photorealistic visualisation. The architectural project manager explained that rendering was not just for representation, but also 'to see how the spaces work, their attuning qualities' (FN-10-17). In the unfolding the rendering of the 3D model the architects added synesthetic layers (like colour, light). This was a process creating a holistic sensory experience of the space and its potential atmosphere, whereby the 3D model would increasingly look as the photo of an existing space. Accordingly the project manager explained that the 'details in 3D have to be correct to get the right effect-affect. It is about detail. That makes the experience.' (FN-10-17). Elaborating further how the basic details, like making a pillar black, while being white in the actual construction, or confusing a glass wall with a concrete wall, would undermine the whole experience. 


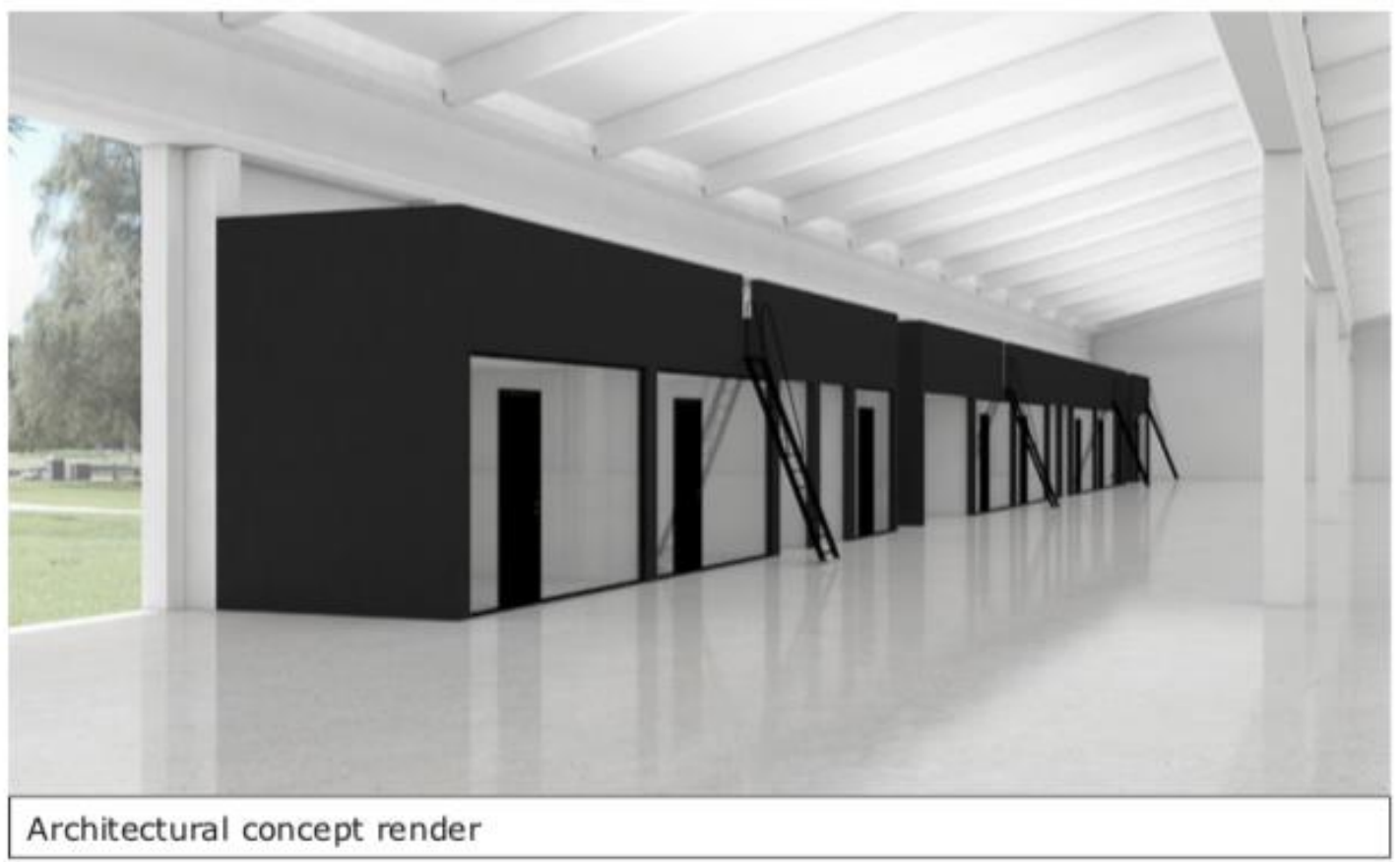

Image 4: Rendering (DG-05-17)

The 3D visualisations, in the first project, found architects engaging themselves affectively in the performative staging of the final design. But the visualisations also allowed clients informed access, where rendering made the space perceptible, as if it already existed (image 4). The architects placed the 3D sketches and renderings in combination with other details in the design guide as to visualize different details of a given space to give overview (Image 5).
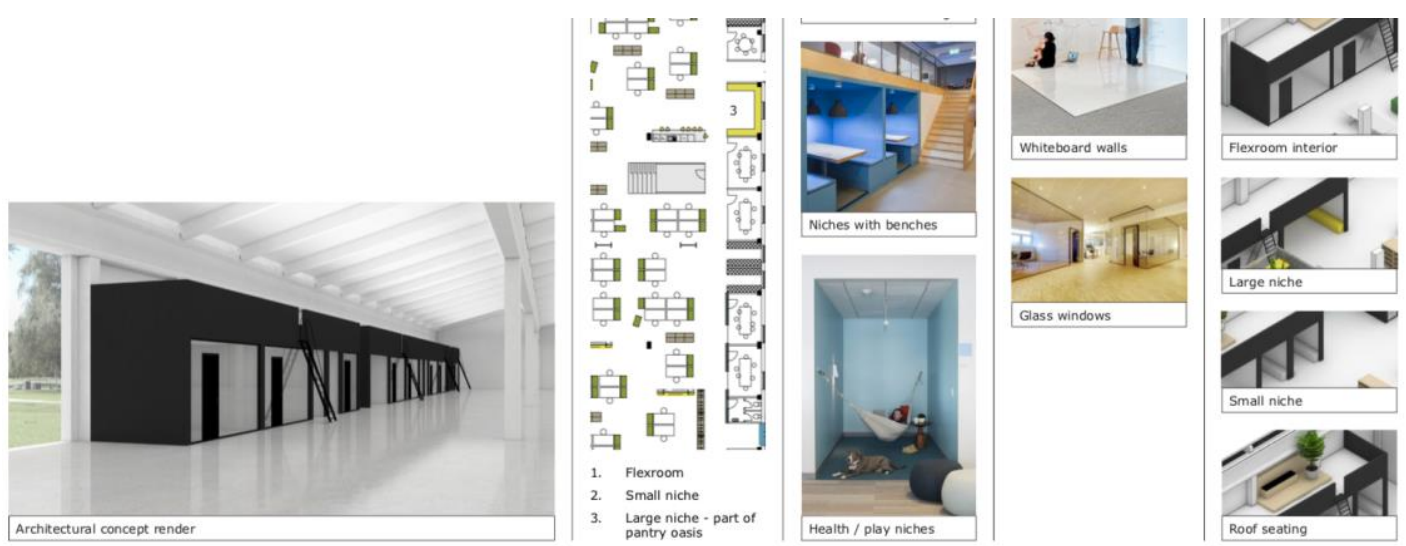

Image 5: Design guide example (DG-05-17) 
The rendering was opened up by adding visualizations of the potential interior as well as connecting that detailed space to the larger office space. The design guide presented the conditions, the totality, that were to let moods emanate and be enacted in the everyday usage. The design guide in itself thereby constituted a zooming in and zooming out of the different space(s) designed, being able to shift between detail and totality, visualizing perspectives, flows and relations, evoking the moods articulated in the design parameters and providing oscillations between whole and part also championed by architects like Zumthor and Pallasmaa (Böhme, 2014: 3).

\section{Creating scenarios}

Essential to architectural design is client involvement to foster to common perspectives on, and engagements with, space. Here 2D models were used to promote an affective engagement in judging how the sensory-affective atmosphere evoked the central client values.

This took place at the second workshop of the second project (FN-8-17). Members of the commissioning organization were gathered for full day workshop. The facilitating architect started by resuming points from the first workshop held before summer. The architects had worked with the input from the organization to convert the conceptual moods into a spatial design. Part of the process was envisaging yet-to-be-lived future space using MicroStation, presenting 2D models by means of detailed drawings of building parts and interior objects. This gave intricate technical specification of measurement and scale, as well as a potential sense of density and flow.

After the resuming the facilitating architect addressed a key focus of the 
workshop, when the architect with determined impetus said 'we can make the space, but you have to use it. The physical space will only be activated by how you use it.' (FN-8-17). The architect exemplified how the choice of colour, materials and lighting are ways to develop a sense of openness or distance, shaping moods rather than beautification. In putting attention on mood, the architect stressed 'it is important that in your workspace you think that this is our space' (FN-8-17), implying people had to feel pulled in and at home in their future space.

As the next step the architect presented 3 different floor plans giving a horizontal cut through of the building. The three 2D layouts ranged from a dense spatial coding with table rows of 8 tables together (Image 6 - left) through a semi-flexible space, to one being open and flexible in terms of activities and flows (Image 6 - right).
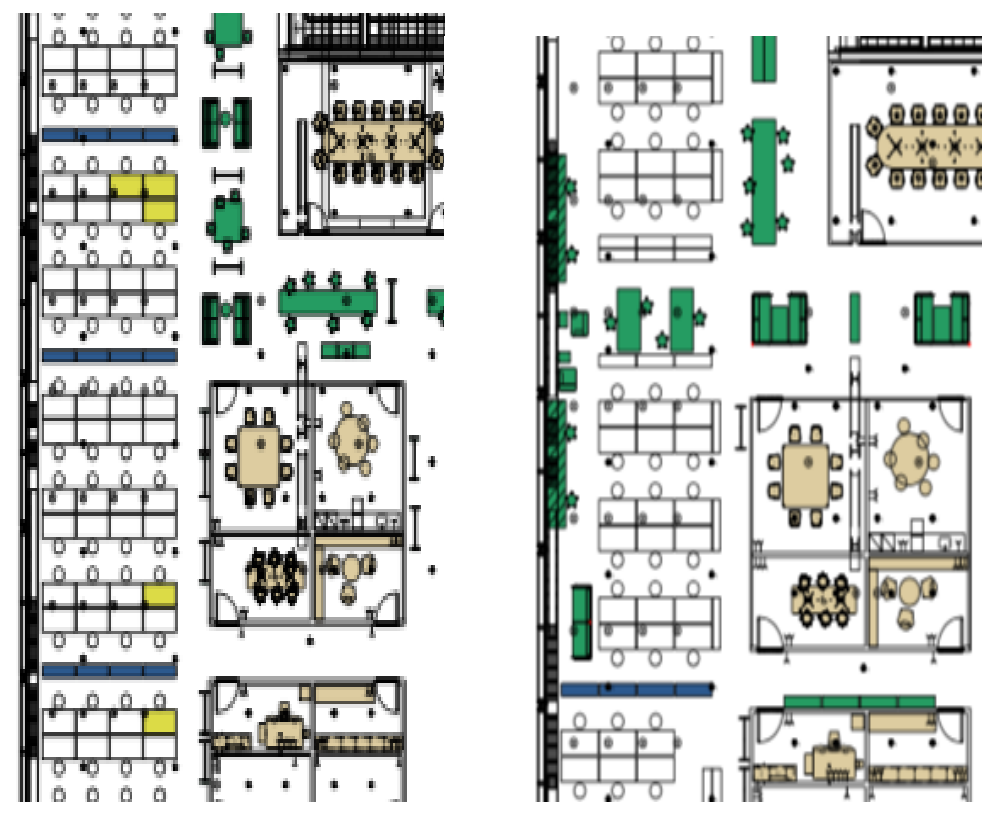

Image 6: Particular first (full seating) and third space (flexible seating) layout (FW-08-17). 
Where the dense coding implied less movement due to more fixed workstations and the open version more, this reflected different spatial versions of relationality in everyday of the organization, creating variation in the sense of spatial contraction and/or expanse. The facilitating architect explained the reason for presenting 3 scenarios, saying 'I find it very important, when we do three scenarios, that they are caricatured, cause otherwise you can't really sense them. In most cases we end up with a hybrid of the three.'(FN-08-17). The layouts prompted joint discussions among the participants on the varieties of activity-based working ${ }^{4}$ principles, functionally aiming for more interactive and flexible office routines. Participants comments stressed the complexity and diversity of work practices, constituting a lot of realities. Comments were the tone of voice, the eagerness or hesitation in the speech shifted according to the challenges or possibilities discussed.

The joint discussion underlined that taking a (radical) turn to activitybased spatial planning, for many organizations not only means physical transitioning, but also an emotional-existential one. The architects aim at evoking affective response to the layout scenarios, asking clients to consider the possible alignments between space and mood, was successfully confirmed by one of the participants in of the workshop, when she afterwards said to the architect: 'I sat in the back of the room. I could really feel how the tension dissolved when we moved from the first space plan (ed. ill. 6 - left) to the more spacious (ed. Ill. 6 - right). Maybe the total free seating, full activity-based is a bit

\footnotetext{
4 Abandoning fixed working desk, the intention is to integrate the flexible possibilities introduced with modern technology and movement by defining activity zones (Duffy, 1997).
} 
to the other extreme, but it certainly gave a great sense of the difference.' (FN08-17).

One of the architects had previously explained that they presented different scenarios of the spatial layout in the design process, as they had experienced that it made it easier for the client organization to relate the different options. In this sense the architects opened a set of worlds for the organization to engage affectively with and to potentially develop as their own in the future. Whereas the full seating created an embodied response in the form tension and restriction, the most open and flexible space was for some equally challenging creating a sensation of exposure and uncertainty. The visualizations in this sense opened for a co-involving dialogue on the feel of the space to become, on how everyday work patterns and the spatial design might co-evolve. Information that was then used to further develop the design reflecting new ways of working, the rhythms of the space and the design parameters atmospheric conditioning, which lead (as predicted) to a hybrid form of the three scenarios. The final layout underlined a space with movement and interaction, presenting points of anchorage via workstations and coloured gathering points. The layout that was developed in the design guide follows from the example below. 


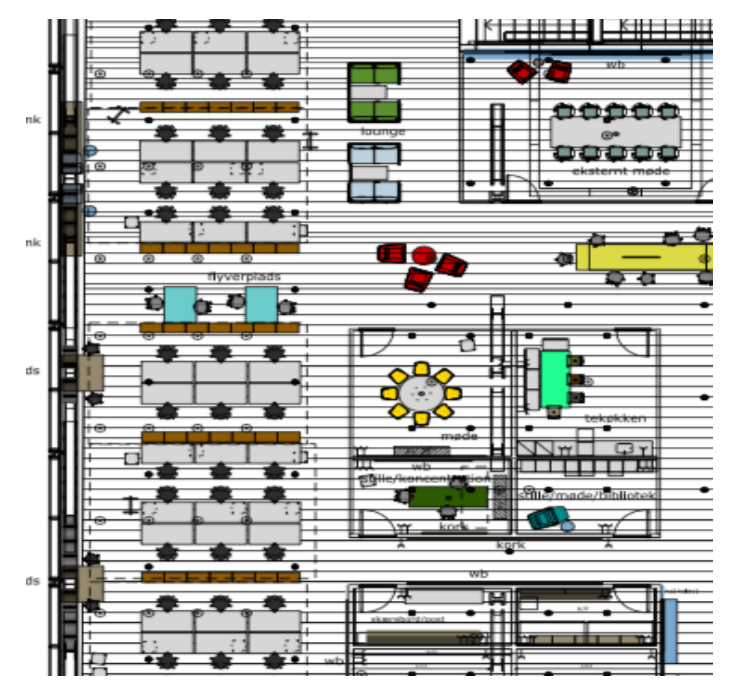

Image 7: Particular from space layout, $2^{\text {nd }}$ project (DG-11-17)

\section{Analysis}

The digital technologies we studied, like many technologies, worked by processing data and imagery that revealed otherwise tacit (everyday habits, feelings) and unknowable (future states) occurrence. This was done by combining mimetic representations and performative visualizations using technology that was mediating the ideas, bodily memories and collective sensitivities of its users. The technology was integral to the design process, allowing the architects and clients to sense not just the emerging shape and functionality of design, but to do so through its atmospheric qualities by attending to its kinesthetic and synesthetic possibilities.

In this respect the digital technologies and visualisations of diverse data, constituted a form of performative staging articulating a sensory-affective access to information. Working with digital technologies created a sense of future interiority, following Sloterdijk (2014: 230ff.), allowing immersion in an embodied experience of future space. There was sustained interest in feelings of 
'pulling in' and 'pushing out' mediated by software, search engines, and social media, but all the while in the company of users struggling conversationally and bodily to imagine how the design could condition small transformations in everyday experience (Ihde, 2009b; Yaneva, 2009; Von Borries, 2017). We find this inwards/outwards atmospheric movement in everyday inhabitation of an office space echoes and enriches Martin's (2003) definition of organization as the technological mediated struggle of an organism to realize cohesiveness and potential. It does so by revealing it to be an affective condition of mood in which values and routines are felt, rather than rationally framed as causes or effects.

The first example elicited a set of organizational values and dispositions, arriving at moods evoking the 'gut feeling' of the organization; an organization is something embodied through technological mediation, in this case through the felt experiences of imagined space (Böhme, 1995; Pallasmaa, 2014; Zumthor, 2005). The example presented how the design parameter love, as a mood, became a sensed and affectively felt value. Technology was used to elicit tacit understandings that refused to cohere in neatly ordered stacks of 'if ... then ...' knowledge, but to what Strati (2010) called the braided sense of self and organizational identity that can only be apprehended with feeling, in this case machine-assisted feeling. We show this braiding to be quite ordinarily and collectively felt. The imagery and software envisaged how these values and dispositions might receive prosthetic expression through the use of office space (Hansen, 2006).

Collectively the processually developed concepts (like 'love') and images (like furniture details) served as allegoric figures telling a narrative of personal and organizational values, habituated into a wider cultural system (Ihde, 2009a). 
This was arrived at in mediated conversation provoked by technologies whose visualizations were invitations to recall feelings. In this way, the image of a chair detail itself mediates an organizational value conceptualized as 'love' by accentuating embodied experience, touching explicitly on otherwise unspoken atmospheric qualities, whilst always keeping its inward force loose enough to allow for outward variation.

This presents a different skew on using digital images than the 'representations' discussed by Degen et al. (2017: 337), where images would show realistically what the new spaces would look like to make developers invest. In studying the 'conscious virtual engineering of sensory experience' Degen et al (2017: 5) argue atmosphere has an economic value in influencing the production and consumption of goods (Degen et al, 2017: 8-9) (they understand its instrumental power), there is a risk of configuring the technology as a tool transmitting managerial intentions, rather than mediating experience. In this sense, their work downplays what Julmi (2016) calls the ontological nature of atmosphere, and Reckwitz (2013) calls the aesthetic, being those forms of sensory-affective experience that lack external legitimation or instrumental warrant; they are interiors without warrants. So where Degen et al (2017: 20) analyse atmospheric production through a means/end pragmatic concern for which technology is most commercially persuasive, our study concentrates how technology mediates sensory-affective experiences in the design process, opening up perspectives and understandings of organization that supplement Beyes and Steyaert's (2011) interest in 'spacing organization' or O’Doherty's fascination with 'the blur sensation' of organization (2008). In our analysis we sense how this spacing or blur might be framed phenomenologically, as a merger 
of inward and outward feeling and forces, which in turn, as technologically mediated atmosphere, come to constitute the struggle for cohesiveness and openness that defines organization.

This is especially apparent in the second example of 3D modelling using Rhino that allowed the architects to sense spatial volumes and their kinaesthetic quality. As virtual reality, the architects can 'walk' the space using their embodied knowledge, wearing the space (Hansen, 2006), sensing how it may feel to move around, to be organized spatially, allowing users to dynamically switch between different spatial arrangements and kinaesthetic experiences unfolding different atmospheric scenarios, revealing where the design might go (Ihde, 2009a).

Users touch on gut feeling, the mood, by emphasizing the kinaesthetic experience, the condition Böhme (1995) considers a grounding feature in the architectural design of atmosphere. Technologically creating (and not representing in appearance) the voluminosity of the space finds digital technologies impressing upon users what it is to be close up and far from things not as they appear, but as they are sensed (Sloterdijk, 2004). In this the technology was revealing space not as a volume to be filled with things set in managed relations, but atmospherically, as an interior constituted in sensoryaffective flows: flex-rooms, for example, were configured through possible impressions rather than just specifications, allowing users to imagine spaces to concentrate (inwards) or share (outwards) (Ihde, 2009b: 33-34).

In the third example, from the second project, the use of digital technologies, like MicroStation, created a set of scenarios for the spatial layout of an open plan office. Creating an embodied experience of tension due to the 
restrictive logic of an enclosed spatial layout or a feeling of uncertainty with a more flexible coding of the spatial layout, presented the affective forces of digital technologies. The digital technology mediated prehensions of how it might feel to work in a new environment by creating an embodied perception of kinaesthetic and synesthetic qualities of the interior space, qualities that Benjamin found so fascinating: how do bodies press upon or release from one another, embodying norms and values through pressures of presence and absence, through the rapidity or stalling of movement, the compliance or resistance.

Here atmosphere is being brought into being by combining felt experiences of pulling inwards and moving outwards, as the design parameter love i.e. reflected relationality and humanity. The sense of going in, of being pressed together, creating a refuge like gathering, was akin to creating a home, of being somewhere present in the present, enabling, hopefully, employees to feel respected and protected in their daily work. The sense of being outward, of not feeling hemmed in by the presence of things, and so remaining exposed to imaginative attraction of difference

Generally, then, from all the three examples, we find digital technology mediating organization through the creation of atmospheres, and at the same time attuning users to their complicity with this conditioning force: users as occupants, rather than beholders of an external, formulaic form. Here, in the spirit of the architect Eileen Gray, atmospheric architecture frees itself from the traded calculations of producing measured, place-less things, and instead looks, to the affects of an interior space on users: "[i]t is not only a matter of constructing beautiful arrangement of lines, but above all dwellings for people" 
(cited in McCarter 2016: 146). Dwellings that take the shape of users inhabiting them, without, however, becoming too enclosed, to cohesive, too obviously managed, which was perhaps the problem with the Arcades (Benjamin, 1999: 865).

This is most apparent in design practice itself. We have found designing with digital technology meant working situationally, as a performance, not simply through mimetic representation. Design becomes itself a conditioning part of an atmospheric whole by which an organization is being imaginatively formed as an interior sufficiently distinct to have a sense of cohesiveness and possibility as set against its multiple exteriors (Böhme 1995; 2013; McCarter, 2016: 138; Pallasmaa, 2014). The use of digital technologies afforded users a sense of oscillating between conditioning and being conditioned, the key atmospheric ambivalence Anderson and Ash mention (2015: 78). Such oscillations underline design as a relational condition, involving the collective sensory-affective engagement of many people, including future users, whose embodied experience of being conditioned is vital to understanding the possibilities for future conditioning.

This talks to Carpo's argument of digital technology challenging Modernist principles by letting 'ornamentation' back in (2016) and architectural authorship (2013). Following Carpo 'ornamentation', as excessive algorithmic shapes and forms, tends to create a 'feeling of alienation' (Carpo, 2016: 83). Likewise, digital technology opening for collaborative practises, constitutes a threat of the architect's authorial status as it reduces the architect to curator and form finder (Carpo, 2013: 60). 
These themes are also articulated in examples shown, firstly when understanding 'ornamentation' as excessiveness in both forms as well as colouring, materialities, light etc., contrasting with stringent purist modernist architecture. Secondly, in creating a collaborative design process where the client organization is part of developing the design. Opting for a collaborative design process may be considered a key element in turning from an instrumental design of atmosphere towards embracing its critical and liberating potential (Böhme, 2013; Sloterdijk, 2014).

Carpo senses a risk of loss here: digital tools have supplanted the older, humanist tradition of designing forms through calculation and disciplined knowledge with a looser sense of crafted intuition. Forms are becoming less and less about conscious formation, and when mediated digitally we have digital simulations that allow the relatively unskilled to rapidly generate different models until intuitively one just fits. For Carpo (2013: 60) "digital tools favour and foster the elimination of humanistic and modern authorship: in one case, to the advantage of social actors and networks; in the other, to the advantage of the equally unpredictable forces of nature and of their capacity to evolve and selforganize." Forms become found, not made, and the finding is a product of headless and heedless network forces, in a way similar to the forces Martin (2003) identifies as prevailing in an open, control society. Whilst we accept there is a sense of both architects and users becoming passive, and so not even curators of their condition, but more akin to button operatives, we also found instances where a collective engagement with making rather than finding was apparent, and the making was fulsome and generative, and occasionally provocative. 
This complicates somewhat the argument that media determine our situation. On the one hand we sense our findings conforms with Martin's (2003) observations that with digital technology we have a networked condition of prosthetic enhancement that tips into intellectual and cognitive dependency. Networked technological mediation distributes agency, information and feeling, and its operations are inseparable from the norms and conditions of meaning (and not truth) by which its use is legitimated. The upshot is an endlessly repeated finding of interior comforts: the machinery thinks and acts on our behalf, our individuality being measured by its lacking utterly the need to assert itself.

Yet from within the design process we noted conscious, open and critical engagement, the lived kicked back, especially so when the task at hand was reoriented away from the design of a fixed object, and toward atmospheric forming. Following Benjamin (1999: 155), atmosphere is one form emerging from the use of digital technology, one in which the very lack of material substance and definitive 'object' gives it substantive heft. In our case, turning the object of digitally mediated design away from what a building was, and towards how an atmosphere acts, led to a dynamic, co-evolving apprehension of cohesiveness and possibility, where the shapes and forms being developed were constantly tested in their relationality to human use, human scale, and human sensation. The emphasis on interiors - the spaces touched by daily living, found exteriors emerging from the inside. At least in part this resonates with Ihde's (2009a) observation that with digital technology we have a networked condition of prosthetic enhancement that can induce intellectual, manual and cognitive dependency, yet can also enhance these human capacities. 
We would claim, then, that interweaving digital technologies in the design of atmospheres (and not objects) brings to the fore the possibilities for lived expression that overspill or disturb the intended ordering of things and their relation that is more typical to forms of spatial organization. Working atmospherically demands an empathy for life, insofar as there is an exposure to making explicit what it is users feel, to having them reflect on their collective styles and practices, to accommodating difference, and to do so openly for all these considerations remain, inevitably, vague. The atmospheric demands an experimental attitude to, or at least openness to, the specificities of a situation, as well as acknowledging the cohesive glue of habit and emboidied values. In thinking atmospherically designers of organizational form acknowledge the hubris of attempting to impose already built ideas. The atmospheric is organization without a detailed plan, without final destination. Instead we have a sensitivity or care towards the pressures of immediate localities, towards habits, and towards differences.

In the coming together of physical and virtual space we sense how it is the body and its movements, and not just perspicuous representation, that enables fruitful merger (Hansen, 2006: 2f.). Where it works well the technology works in combination with users, their collective memory and habits of using things. It extends the reach for human action and thought into space that is being imaginatively felt into existence. By emphasising the spatial perspective and its intimacy to the felt human body, we show how technology can enhance, in part, human awareness, rather than restricting it or replacing it with the illusory world promised by 'total technical simulacrums' (Hansen, 2006: 5). Throughout the very ordinary and unspectacular instances of tool use that we observed we 
found in technological mediation less an alternative reality than a broadening of reality made possible by the prompting of memories and associations that fostered an open and collective sense of belonging to somewhere, of being placed, and of this feeling of being placed, of dwelling being a grounding human concern. As Zumthor observes, to become anything, we first need a place from which to strike out, and to which we can return, and this interior is configured not just as a social ordering, but also and more basically as a sensory-affective order of attunement.

To follow Sloterdijk $(2014,153)$, in designing atmospherically, the architectural things are not just configurations of form and function, but present themselves by way of a gift by which an interior comes into being, or as he says, reflecting on Daniel Libeskind's architecture: 'it is a proposal for immersion into spatialized freedom.' (Sloterdijk, 2014: 293). Following Sloterdijk (2014: 293ff.), we open up for a conception of architectural collaboration in which people have an active, open involvement, rather than just taking part passively as an audience. ${ }^{5}$ In this it is an expression of a wider conceptualization of all spatially understood, technologically mediated organizational forces as being both restrictive (cohesiveness, belonging, identity) and expansive (generosity, ethics, innovation and creativity). Whilst we confine our study to design of architectural interiors, the same might be found ifn studies of legal structures, say, or bureaucracies.

\section{Conclusion}

\footnotetext{
5 The English translation uses participatory, which we felt too broad to convey what is an immersed and involved form of productive dwelling with things; it is more than just taking part.
} 
New technologies have opened new perspectives on the appearance of space in architectural practice, which we have shown interweave with discussions in organizational studies on the spatial, aesthetic, affective and atmospheric dimensions of organization. In our study, we have investigated how digital technology informs architectural interior design practices, based on the claim that digital technologies mediate the affective and atmospheric qualities of space in such a way that they show how we might get at the nature of organization.

The examples studied showed different ways technology affords an embodied experience of interior space and atmosphere as performative sceneries. The focus on the design on atmosphere accentuated the qualities of digital technologies as mediator of affective-sensory experience. Further it stressed the design process as a relational approach involving the client organization in designing the atmospheric conditions, which were to co-evolve with organizations everyday life. Looking at the design of atmosphere through architectural design practise not only addresses the mediating quality of digital technologies, but also constitutes a relational approach to design and organization. This perspective adds another perspective on design pointing towards a collaborative practise emphasising the potentiality of organization, atmosphere - and digital technologies. Focusing on the potentiality we would however encourage for approaching the experience of the users of atmospheric architecture. Likewise we consider the discussion on collaboration, in contrast to participation, in the design process would be apt for further investigation as to unfold the notion of relationality both in practice and conceptually. 


\section{References}

Ahrne, G. \& N. Brunsson (2011). “Organization outside Organizations: The Significance of Partial Organization", Organization, 18(1): 83-104 Aksamija, A. (2016). Integrating Innovation in Architecture, Chichester: Wiley. Anderson, B. \& Ash, J. (2015). "Atmospheric Methods", P. Vannini, NonRepresentational Methodologies: Re-Envisioning Research, pp. 77-81. New York: Routledge Anderson, B. (2016). Encountering Affect, New York: Routledge Ash, J. \& P. Simpson (2016). "Geography and post-phenomenology", Progress in Human Geography, vol. 40(1), pp.48-66

Benjamin, W (1999) The Arcades Project. H Eiland and K McLaughlin trans.. Cambridge, Mass.: Belknap Press.

Beyes, T. \& Steyaert, C. (2011). "Spacing organization: non-representational theory and performing organizational space", Organization, vol. 19(1), pp. 45-61. Biehl-Missal, B. \& Saren, M. (2012). "Atmospheres of Seduction: A Critique of Aesthetic Marketing Practices", Journal of Macromarketing, vol. 32(2), pp. 168180.

Bille, M., Bjerregaard, P. \& Tim F. Sørensen (2013). "Staging atmospheres: Materiality, culture, and the texture of the in-between", Emotion, Space and Society, vol. 15, pp. 31-38.

Böhme, Gernot. 2014. "Encountering Atmosphere: A Reflection on the Concept of Atmosphere in the Work of Juhani Pallasmaa and Peter Zumthor." OASE 91 Building Atmosphere: 93-10.

Böhme, G. (2013). Architektur und Atmosphäre, München: Wilhelm Fink.

Böhme, G. (2001). Aisthetik, Vorlesungen über Ästhetik als allgemeine Wahrnehmungslehre, München, Wilhelm Fink.

Böhme, G. (1995). Atmosphäre, Essays zur neuen Ästhetik, Frankfurt am Main: Suhrkamp. 
Borch, C. (2010). "Organizational Atmospheres: Foam, Affect and Architecture", Organization, vol. 17(2), pp. 223-241.

Burrell, G. \& Dale, K. (2008). Spaces of Organization and the Organization of Space. Basingstoke: Palgrave Macmillan

Carpo, Mario. 2016. “Excessive Resolution: From Digital Streamlining to Computational Complexity." Architectural Design 86(6): 78-83.

Carpo, Mario. 2013. “The Ebb and Flow of Digital Innovation: From Form Making to Form Finding - and Beyond" eds. Pia Ednie-Brown, Mark Burry, and Andrew Burrow. Architectural Design 83(1): 56-61.

Charitos, D. \& Theona, I. (2016). "Investigating the atmosphere of pervasive and ubiquitous computing mediated spatial experiences: a post-phenomenological approach, Ambiances, tomorrow". Proceedings of $3^{\text {rd }}$ International Congress on Ambiances, Sept. 2016, Volos, Greece. International Network Ambiances: University of Thessaly, vol.1, pp. 443-448

Christensen, P. (2007). Motivation i videnarbejde, Copenhagen: Hans Reitzel Clear, Nic. 2013. “Drawing Time” ed. Neil Spiller. Architectural Design 83(5): 7079.

Clegg, S \& Kornberger, M., (2006). Space, Organizations and Management Theory, Copenhagen: Liber\&CBS Press.

de Vaujany, F. and E. Vaast (2014). "If these walls could talk: The mutual construction of organizational space and legitimacy", Organization Science 25(3): 713-731.

Degen, M. et al. (2017). "Producing place atmosphere digitally: Architecture, digital visualization practices and the experience economy", Journal of Consumer Culture, vol. 17(1), pp. 3-24.

Diamond, Sara. 2010. "Lenticular Galaxies: The Polyvalent Aesthetics of Data Visualitzation." CTheory.

Duffy, F. (1997). The new office, London: Conran Octopus

Hansen, M. (2006). Bodies in Code, New York: Routledge

Hansen, M. (2009). "Movement and Memory: Intuition as Virtualization in GPS Art”, Comparative Literature Issue, vol 120(5), pp.1206-1225

Hansen, P. (2018) Danish Modern Furniture 1930-2016. University Press of Southern Denmark. 
Hasse, J. (2015). Was Räume mit uns machen - und wir mit ihnen, München: Karl Alber.

Heibach, C. (2012). Atmosphären, Dimensionen eines diffusen Phänomens, Paderborn: Fink.

Ihde, D. (2009a). "From Da Vinci to CAD and beyond". Synthese vol.168, pp.453467

Idhe, D. (2009b). Postphenomenology and Technoscience, New York: SUNY Press

Julmi, C. (2016). "The concept of Atmosphere in Management and Organization Studies", Organizational Aesthetics, vol. 6(1), pp.4-30

Julmi, C. (2015). Atmosphären in Organisationen, Bochum: Projektverl.

Kolarevic, B. (2001) "Designing and Manufacturing Architecture in the Digital Age." Architectural Information Management: 19th eCAADe Conference Proceedings, 117-123. eCAADe: Conferences. Helsinki, Finland: Helsinki University of Technology (HUT).

Lefebvre, H. (1974/1991). The Production of Space. Translated by D. NicholsonSmith. Oxford: Blackwell.

Martin, Reinhold. 1998. "The Organizational Complex: Cybernetics, Space,

Discourse." Assemblage 37: 102-27.

Martin, R (2003) The Organizational Complex. Cambridge, Mass.: MIT Press.

McCarter, R (2016) The Space Within. London: Reaktion Books.

Michels, C. \& Steyaert, C. (2016). "By accident and by design: Composing affective atmospheres in an urban art intervention", Organization, pp.1-20

Michels, C. (2015). "Researching affective atmospheres”, Geographica Helvetica, vol. 70 , pp.255-263

O’Doherty, Damien. 2008. "The Blur Sensation: Shadows of the Future.” Organization 15(4): 535-61.

Oxman, R. (2017). “Thinking difference: Theories and models of parametric design thinking", Design Studios, vol 52, pp. 4-39

Pallasmaa, J. (2014). "Space, place, atmosphere", Lebenswelt, vol. 1(4), pp. 230245.

Pink, S., Mackley, K.L. \& Morosanu, R. (2014). “Researching in Atmosphere: video and the 'feel' of the mundane", visual communication, vol. 14(3), pp. 351-369 
Potthast, J. (1998). Sollen wir mal ein Hochhaus bauen?, Berlin:

Wissenschaftszentrum Berlin für Sozialforschung

Rauh, A. (2012). Die besondere Atmosphäre, Ästhetische Feldforschungen,

Bielefeld: transcript Verlag.

Reckwitz, Andreas. (2016). "How Senses Organize the Social." In Praxeological

Political Analysis, eds. Michael Jonas and Beate Littig. London: Routledge Ltd, $56-66$.

Reckwitz, A. (2013). Die Erfindung der Kreativität, Berlin: Suhrkamp.

Schmidt, Ulrik. 2016. “Datamasser Og Sansemiljøer.” MedieKultur 59: 28-49.

Schmitz, H. (2014). Atmosphären, München: Karl Alber.

Shortt, H. (2014). "Liminality, space and the importance of 'transitory dwelling places' at work", Human Relations, 68(4): 633-658.

Sloane, M. (2014). "Tuning the space: investigating the making of atmospheres through the interior design practices", Interiors: Design, Architecture and Culture, vol. 5(3), pp. 297-314

Sloterdijk. P (2017) The Architectural Imperative. Trans. Karen Margolis. Cambridge: Polity Press.

Sloterdijk, P. (2014). Der ästhetische Imperativ, Frankfurt am Main: Suhrkamp. Sloterdijk, P. (2012). The Art of Philosophy. Translated by Karen Margolis. New York: Columbia University Press.

Sloterdijk, P. (2004). Sphären III, Frankfurt am Main: Suhrkamp.

Strati, A. (2010). Aesthetic Understanding of Work and Organizational Life, Oxford: Oxford University Press.

Sumartojo, Shanti, Sarah Pink, Deborah Lupton, and Christine LaBond. 2016.

“The Affective Intensities of Datafied Space." Emotion, Space and Society 21: 3040.

Tyler, M. and Cohen, L. (2010) "Spaces that Matter: Gender Performativity and Organizational Space”, Organization Studies 31(2): 175-198.

Tripathi, A. (2015). "Postphenomenological investigations of technological experience", AI\& Soc, vol. 30, pp. 199-205.

Von Borries, F. (2017): Weltentwerfen - Eine politische Designtheorie, Berlin, Suhrkamp

Wiertelarz, K. (2015): Processes of Making. Algorithmic methods in architectural 
practise, Kassel: Kassel University Press

Yaneva, A. (2017). Five Ways to Make Architecture Political, London: Bloombury Yaneva, A. (2009). The Making of a Building, UK: Peter Long

Zumthor, P. (2005). Atmospheres, Basel: Birkhäuser. 